\title{
Sözlü Bilgilendirmenin Bronkoskopi Öncesi Kaygıya Etkisi
}

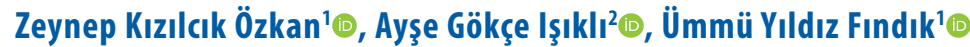

'Trakya Üniversitesi Sağlık Bilimleri Fakültesi, Cerrahi Hastalıkları Hemşireliği Anabilim Dalı, Edirne, Türkiye

${ }^{2}$ Trakya Üniversitesi Sağlık Araştırma ve Uygulama Merkezi, Göğüs Cerrahisi Servisi, Edirne, Türkiye

Zeynep Kızılcık Özkan, Arş. Gör. Dr. Ayşe Gökçe Işıkı, Hemşire Ümmü Yıldız Fındık, Prof. Dr.
Illetişim:

Arş. Gör. Dr. Zeynep Kızılcık Özkan

Trakya Üniversitesi Sağık Bilimleri Fakültesi, Cerrahi Hastalıkları Hemşireliği Anabilim Dalı, Edirne, Türkiye

Tel: $+902842133042 / 1027$

E-Posta: zeynepkizilcik26@hotmail.com
ÖZET

Amaç: Bu vaka kontrol çalışmasının amacı; bronkoskopi uygulanan hastalarda bronkoskopi hakkında sözlü bilgilendirme yapmanın, kaygı düzeyi üzerine etkisini değerlendirmektir.

Çalışma Planı: Bu çalışma Şubat 2017- Şubat 2018 tarihinde bronkoskopi yapılan 60 gönüllü hastanın katılımıyla gerçekleştirildi. Verilerin toplanmasında "Hasta Tanım Formu" ve "Durumluk Süreklilik Kaygı Ölçeği" ve "Hasta Bilgilendirme Formu" kullanıldı. Verilerin analizinde bağımsız örneklem t test ve Ki kare testlerinden yararlanıldı.

Bulgular: Çalışmaya katılan hastaların \%70'inin erkek olduğu ve yaş ortalamasının 59,78 $\pm 10,72$ yıl olduğu saptandı. Deney ve kontrol grupları arasında durumluk ve süreklilik kaygı düzeylerine göre istatistiksel açıdan anlamIı fark olmadığı belirlendi $(p>0,05)$.

Sonuç: Hastaların işlem öncesi durumluk ve süreklilik kaygı düzeylerinin orta düzeyde olduğu saptandı. İşlem öncesi sözlü bilgilendirme yapmanın bronkoskopi öncesi durumluk ve süreklilik kaygı düzeylerinin azaltılmasında tek başına etkili olmadığı belirlendi.

Anahtar sözcükler: Bronkoskopi, kaygı, sözlü bilgilendirme

\section{THE EFFECT OF VERBAL INFORMATION ON PREBRONCHOSCOPY ANXIETY}

\section{ABSTRACT}

Objectives: This case-control study aimed to determine the effect of verbal information on the anxiety of patients undergoing bronchoscopy.

Study Design: This study was carried out between February 2017 and February 2018 on 60 voluntary patients undergoing bronchoscopy. In data collection, "Patient Descriptive Form", "State-Trait Anxiety Scale" and "Patient Information Form" were used. In data analysis, independent samples t-test and chi-square tests were used.

Results: In the present study, the mean age of patients was $59.78 \pm 10.72,70 \%$ were male. There was not a statistical difference in the mean for the state and trait anxiety scores between case and control groups $(p>0.05)$.

Conclusion: The pre-procedural state and trait anxiety levels of the patients were found to be moderate. This study demonstrated that before the procedure, verbal informing to the patients alone was not effective in reducing the state and continuity of anxiety levels before bronchoscopy.

Keywords: Bronchoscopy, anxiety, verbal information

ronkoskopi; bronkoskop adı verilen fleksibl, ince ve ucunda kamera bulunan bir tüple ağızdan veya burundan girilerek trakeabronşiyal dalların ve bronkopulmoner segmentlerin görüntülenmesine ve pulmoner sistem hastalıklarının tanılanmasına veya tedavi edilmesine olanak sağlayan bir yöntemdir (1). 
Bronkoskopiyle biyopsi materyali alma, bronşiyal lavaj, yabancı cisim çıkarma, stenoz dilatasyonu, stent yerleştirme, tümör rezeksiyonu gibi işlemler tanı ve tedavi amaçlı olarak uygulanmaktadır $(1,2)$.

Bronkoskopi boğulma hissi ve öksürük oluşturan (3) invaziv bir işlem olduğundan (4) kişilerde korku, rahatsızlık hissi ve kaygıya yol açabilmektedir $(5,6)$. Yılmaz (2012) çalışmasında hastaların bronkoskopi öncesinde canım acıyacak mı, uyutulacak mıyım gibi sorular sorduğunu tespit etmiştir (7). Poi ve ark. (1998) ise bronkoskopi uygulanacak hastalarda bronkoskopiden bir gün önce ve işlem gününde hastaların kaygı skorlarının yükseldiğini belirlemiştirler (8). Türkeli ve ark. (2016) çalışmalarında bronkoskopi uygulanacak olan pediatrik hastaların sağlıklı çocuklara göre kaygı düzeylerinin yükseldiği belirlenmiştir (9). Bernasconi (2009) ve Tetikkurt ve ark.(2014) çalışmalarında işlem öncesi yüksek kaygı düzeylerinin hastaların işlem tolerasyonlarını azalttığını ve huzursuzluk hissetmelerine neden olduğunu belirtmiştirler $(5,6)$. Mitsumune ve ark. (2005) yüksek kaygı düzeyinin işlem konforunu etkileyen bağımsız bir faktör olduğunu tespit etmiştirler (10). Literatüre baktığımızda hastaların deneyimledikleri kaygıyı azaltmak adına müzikoterapi (4), refleksoloji (11) ve multimedya (12) uygulamalarından yararlanıldığı görülmüştür. Bu yöntemlerin etkin olduğunu belirten çalışmaIarın (13) yanında etkin olmadığını bildiren çalışmalar da $(4,12)$ literatürde yer almaktadır.

Bu çalışma, bronkoskopi uygulanan hastalarda işlem öncesi bronkoskopi hakkında sözlü bilgilendirme yapmanın, kaygı üzerine etkisini değerlendirmek amacı ile yapıldı.

\section{Araştırma soruları?}

1. Bronkoskopi uygulanan hastaların işlem öncesi durumluk ve süreklilik kaygı düzeyleri nedir?

\section{Gereç ve yöntem}

Araştırmanın türü

Bu çalışma vaka kontrol türünde yapıldı.

\section{Araştırmanın evren ve örneklemi}

Bu çalışma El-Hassan ve arkadaşlarının 2008 yılında yaptıkları çalışmadaki (Clinical trial: music reduces anxiety levels in patients attending for endoscopy)(14) bulguların dahilinde durumluk kaygıya ilişkin saptanan standart sapma değerine göre ( $\mathrm{SS}=6.9$ ) \%95 güven düzeyinde, $\% 5$ tolerans oranı öngörerek her grup 30 kişiden oluşmak üzereörnekleme alınması gereken en az kişi sayısı 60 olarak bulunmuştur. Çalışmaya dahil edilme kriterleri;
1. Göğüs cerrahi servisi bronkoskopi ünitesinde bronkoskopi işlemi yapılacak olan bireyler,

2. Çalışmaya katılmaya gönüllü bireyler,

3. Mental yeterliliği olan bireyler,

4. 18 yaşını doldurmuş olan bireyler,

5. Türkçe iletişim problemi olmayan bireyler,

6. Göğüs cerrahi servisinde yatarak tedavi gören,

7. Görme ve duyma problemi olmayan bireyler olarak belirlenmiştir.

\section{Araştırmanın yapıldığı yer}

Araştırma Edirne ili merkezinde yer alan yurtiçinden olduğu kadar Balkan ülkelerinden gelen hastalara da sağlık hizmeti sunan bir üniversitenin göğüs cerrahi servisi bronkoskopi ünitesinde gerçekleştirilmiştir.

\section{Veri toplama araçları}

Hasta tanım formu; bireysel değişkenlere (5), bronkoskopi işlemine (5) ilişkin soruları içeren 10 sorudan oluşmaktadır.

Durumluk ve Süreklilik Kaygı Ölçeği; durumluk ve sürekli kaygı seviyelerini ayrı ayrı saptamak amacıyla Spielberg ve arkadaşları tarafından (1970) geliştirilmiş, Öner ve Le Compte tarafından Türkçe geçerlilik ve güvenilirliği yapılmıştır. 14 yaş üstü bireylere uygulanabilmektedir. Ortalama 10 dakika sürmektedir. Durumluk Kaygı Ölçeği, belirli bir anda ve belirli koşullarda kendini nasıl hissettiğini belirleyen ve 20 ifadeden oluşan bir öz-değerlendirme ölçeği iken, Sürekli Kaygı Ölçeği ise; bireyin içinde bulunduğu durum ve koşullardan bağımsız olarak kendini nasıl hissettiğini belirleyen 20 adet ifade içermektedir. Ölçekte düz ve ters ifadeler yer almaktadır. Durumluk Kaygı Ölçeğinde 10 tane ters $(1,2,5,8,10,11,15,16,19$ ve 20.maddeler) ve 10 tane düz ifade vardır. Süreklilik Kaygı Ölçeğinde 7 adet ters (21, 26, 27, 30, 33, 36 ve 39. maddeler) ve 13 adet düz ifade bulunmaktadır. Düz ifadeler; olumsuz duyguları, ters ifadeler ise olumlu duyguları dile getirir. Ters ifadeler puanlanırken 1 ağırlık değerinde olanlar 4'e, 4 ağırlık değerindekiler ise 1'e dönüşür. Düz ifadelerde 4 değerindeki cevaplar kaygının yüksek olduğunu gösterir. Ters ifadelerde ise, 1 değerindeki cevaplar yüksek kaygıyı, 4 değerindekiler ise düşük kaygı seviyesini gösterir. Doğrudan ifadeler için elde edilen toplam ağırlıklı puandan, ters ifadelerin toplam ağırlıklı puanı çıkartılır ve bu sayıya değişmeyen bir değer eklenir. Bu değer Durumluk Kaygı Ölçeği için 50, Sürekli Kaygı Ölçeği için ise 35'dir. Her ölçekte 20-80 arasında puanlandırılmaktadır. Puanın yüksek olması kaygı seviyesinin yüksek olduğuna işaret etmektedir. Cronbach alpha katsayısının durumluk kaygı ölçeği için 0,94-0,96, süreklilik kaygı için 0,83-0,87 
arasında olduğu belirtilmektedir (15). Çalışma kapsamında Cronbach alpha katsayısı durumluk kaygı ölçeği için 0,5 süreklilik kaygı için 0,7 olarak belirlendi.

Hasta Bilgilendirme Formu: servisin bronkoskopi işlem prosedürleri göz önünde tutularak araştırmacılar tarafından hazırlanmıştır. Formda bronkoskopi öncesi, sırası ve sonrasında hasta bakımı ve bilgilendirmesini içeren (örneğin; oral alım durdurulma zamanı, işlem süresi, monitorizasyon gerekliliği vb.) 23 madde yer almaktadır

\section{Verilerin toplanması}

Göğüs cerrahi servisi bronkoskopi ünitesine bronkoskopi için başvuran bireylere araştırmacı çalışmayı, çalışma amacını, önemini ve araştırmacı hakkında bilgilerini verdikten sonra bireylerden bilgilendirilmiş gönüllü olurları sözlü olarak alındı. İşlem günü hasta tanım formunda ve Durumluk-Süreklilik Kaygı Ölçeğinde yer alan sorular araştırmacı tarafından sorularak formlar dolduruldu. Çalışmaya dahil edilme kriterlerine uyan ilk 30 hasta deney sonraki hastalar kontrol grubuna kabul edildi. Kontrol grubundaki hastalara bronkoskopi işlemine yönelik standart bakım verildi. Deney grubundaki hastalara standart bakıma ek olarak yardımcı araştırmacı (AGI) tarafından bronkoskopi odasında bronkoskopi işlemi ve işlem öncesi sırası ve sonrası hemşirelik bakımı hakkında "Hasta Bilgilendirme Formu" baz alınarak işlem öncesinde sözlü bilgi verildi. Bilgilendirme sırasında hastaların soru sormasına izin verildi ve soruları cevaplandırıldı. Bilgilendirmenin süresi $30 \mathrm{dk}$. ile sınırlı tutuldu.

\section{Verilerin değerlendirilmesi}

Çalışma sonucunda elde edilen verilerin analizi SPSS 20.0 paket programında yapıldı. Tanımlayıcı istatistikler değişkenler için (yaş, cinsiyet vb.) ortalama, standart sapma, yüzde, frekans biçiminde gösterildi. Ayrıca normal dağı̆ım gösteren verilerde $t$ test vb. parametrik testler, normal dağılım göstermeyen testlerde de Ki kare vb. nonparametrik testlerden yararlanıldı. Sonuçlar için $p<0.05$ istatistiksel olarak anlamlı kabul edildi.

\section{Araştırmanın etik boyutu}

Çalışma öncesinde hastanenin başhekimliğinden kurum izni ve üniversitenin Tıp Fakültesi Bilimsel Araştırmalar Etik Kurulu'ndan etik kurul izni alındı (TÜTF-BAEK 2017/07, karar no:02/23). Çalışmaya katılan hastalar verdikleri bilgilerin yalnızca bilimsel amaç için kullanılacağı ve gizliliklerinin korunacağı hakkında bilgilendirilerek kendilerinden sözlü olarak bilgilendirilmiş gönüllü olurları alındı.

\section{Araştırmanın sınırlılıkları}

Çalışma sonuçları örnekleme alınan grupla sınırlıdır.

\section{Bulgular}

Çalışmaya katılan hastaların \%70'inin erkek; \%77'sinin ilköğretim mezunu, \%31,7'sinin bronkoskopi deneyimi olduğu ve yaş ortalamasının $59,78 \pm 10,72$ yıl olduğu saptandı. Deney ve kontrol grupları arasında bireysel değişkenlere göre istatistiksel açıdan anlamlı bir fark olmadığı belirlendi (Tablo 1).

Deney ve kontrol grubu hastalarında durumluk ve süreklilik kaygı düzeylerinin işlem öncesinde orta düzeyde olduğu ve gruplar arasında anlamlı fark olmadığı belirlendi ( $p>0.05$ ) (Tablo 2).

\section{Tablo 1. Hastaların bireysel değişkenlere göre dağlımı $(n=60)$}

Bireysel değişkenler

\begin{tabular}{|c|c|c|c|}
\hline Yaş (Ort $\pm S s)$ & & $59,78 \pm 10,72$ & $p=0,576$ \\
\hline \multirow{2}{*}{ Cinsiyet } & Kadın & $18(30)$ & \multirow{2}{*}{$\begin{array}{c}X^{2}=0,714^{* *} \\
p=0,398\end{array}$} \\
\hline & Erkek & $42(70)$ & \\
\hline \multirow{3}{*}{ Eğitim düzeyi } & Illköğretim & $46(77)$ & \multirow{3}{*}{$\begin{array}{c}X^{2}=1,070^{* *} \\
p=0,301\end{array}$} \\
\hline & Lise & $9(15)$ & \\
\hline & Lisans ve üstü & $5(8)$ & \\
\hline \multirow{2}{*}{$\begin{array}{l}\text { Bronkoskopi } \\
\text { deneyimi }\end{array}$} & Evet & $19(31,6)$ & \multirow{2}{*}{$\begin{array}{c}X^{2}=0,309 * * \\
p=0,579\end{array}$} \\
\hline & Hayır & $41(68,3)$ & \\
\hline
\end{tabular}

*Bağımsız örneklem t testi, **Ki-kare

Tablo 2. Hastaların kaygı düzeylerinin dağılımı $(n=60)$

\begin{tabular}{lccc}
\hline Kaygı düzeyleri & Deney grubu & Kontrol grubu & istatistiksel değer \\
\hline Durumluk kaygı & $41,70 \pm 10,37$ & $40,76 \pm 10,73$ & $\begin{array}{c}X^{2}=25,333^{*} \\
p=0,828\end{array}$ \\
Süreklilik kaygı & $45,33 \pm 8.84$ & $44,13 \pm 8,42$ & $\begin{array}{c}X^{2}=22,667 * \\
p=0,652\end{array}$ \\
\hline *Ki kare & & &
\end{tabular}

\section{Tartışma}

Çalışmaya katılan hastaların çoğunluğunun \%(70) erkek ve yaş ortalamasının $59,78 \pm 10,72$ olması literatürle uyumlu bulundu. Triller ve ark. (2005) çalışmalarında bronkoskopi yapılan hastaların $\% 70,5^{\prime}$ inin erkek olduğu ve yaş ortalamalarının 59,1 olduğu belirlemiştirler (13). Bronkoskopinin akciğer kanserinin tanı ve evrelendirilmesi için kullanılması (16) ve akciğer kanserinin tüm dünyada erkeklerde en sık gözlenen kanser türü olması (17) çalışmada erkek oranının yüksek olmasının nedeni olarak gösterilebilir. 
Gruplar arasında hastaların durumluk ve süreklilik kaygı düzeylerinin işlem öncesinde farklılık göstermediği belirlenirken ( $p>0.05)$, benzer şekilde Colt ve ark. (1999) bronkoskopi yapılan hastaların örneklemi oluşturduğu çalışmalarında müzik dinlemenin durumluk kaygı düzeylerini etkilemediğini belirlemiştir (4). Günay ve ark. (2014) çalışmalarında vaka grubu bilgilendirilmiş onam ile bilgilendirirken, deney grubu multimedya eğitim araçları kullanarak bilgilendirmiş ancak bronkoskopi hastalarının durumluk ve süreklilik kaygı düzeylerinin değişmediğini tespit etmiştirler (12). Choi ve ark. (2016) bronkoskopi öncesi hekim tarafından sözlü mesajlarla empatik yaklaşımda bulunduğu hastaların kontrol grubuna göre ve sözlü mesajlara ek olarak dokunma ile hastalarına destek verilen hastaların kontrol grubuna göre kaygılarının anlamlı derecede düşük olduğunu belirtmektedirler (18). Navidian ve ark. (2016) çalışmalarında bronkoskopi sırasında dikkat dağıtıcılardan yararlanmanın hastaların kaygı düzeylerinde istatistiksel açıdan anlamlı düzeyde fark

\section{Kaynaklar}

1. Erdil F, Elbaş N. Cerrahi Hastalıkları Hemşireliği. Ankara: Aydoğdu Ofset Matbaacılık; 2012.

2. Karadakovan A, Aslan FE. Dahili ve Cerrahi Hastalıklarda Bakım. Adana: Nobel Tıp Kitabevleri; 2011.

3. Annakkaya AN, Bedirhan I, Tozkoparan E, Özkan M, Yüksekol I, Bilgiç $\mathrm{H}$, ve ark. Fiberoptik Bronkoskopi Sırasında Hasta Pozisyonu:Oturarak mı? Yatarak mı?. Solunum Hastalıkları 2003; 14: 266-74.

4. Colt $H$, Powers A, Shanks T. Effect of Music on State Anxiety Scores in Patients Undergoing Fiberoptic Bronchoscopy. Chest 1999;116:81924. [CrossRef]

5. Tetikkurt C, Yaşar I, Tetikkurt S, Yılmaz N, Kara BY, Yavuz R, ve ark. Role of Anxiety on Patient Intolerance During Bronchoscopy. Br J Med Med Res 2014; 4: 2171-80.

6. Bernasconi M, Chhajed PN, Müller P, Borer H. Patients' Satisfaction with Flexible Bronchoscopy in a Hospital-based Community Practice. Respiration 2009; 78: 440-5. [CrossRef]

7. Yılmaz PÖ. Bronkoskopi İşleminde Video Bilgilendirmenin Aydınlatılış Onam ve Anksiyete Üzerine Olan Etkisi. Adnan Menderes Üniversitesi Tıp Fakültesi. Uzmanlık tezi. Aydın. 2012

8. Poi RJH, Chuah SY, Srinivas P, Liam CK. Common Fears of Patients Undergoing Bronchoscopy. Eur Respir J 1998; 11: 1147-49. [CrossRef]

9. Türkeli A, Yılmaz Ö, Topçu İ, Yüksel H. The Effect of Flexible Bronchoscopy on Anxiety in Children. Turk Thorac J 2016; 17: 100-4. [CrossRef]

10. Mitsumune T, Senoh E, Adachi M. Prediction of Patient Discomfort During Fiberoptic Bronchoscopy. Respirol 2005; 10: 92-6. [CrossRef] oluşturduğunu tespit etmişlerdir (19). Shahsavari ve ark. (2017) refleksoloji uygulamasının bronkoskopi hastalarının kaygılarını azaltmada etkin olduğunu belirtmektedirler (11). Çalışma sonuçları tek başına bilgilendirmenin bronkoskopi hastalarında kaygı düzeylerine etki etmediğini göstermektedir.

\section{Literatüre katkı}

Bu çalışma, bronkoskopi ve kaygı düzeyini ele alan sınırlı sayıdaki hemşirelik çalışmalarına katkı sağlamıştır. Gelecek çalışmalarda sözlü bilgilendirmenin farklı örneklem gruplarında etkisinin, kaygıyı azaltmaya yönelik diğer yöntemlerin etkinliğinin ve kaygıya etki eden faktörlerin incelenmesini önermekteyiz.

\section{Sonuç}

Çalışma sonuçları ışığında işlem öncesi sözlü bilgilendirme yapmak bronkoskopi öncesi durumluk ve süreklilik kaygı düzeylerinin azaltılmasında tek başına etkili değildir.

11. Shahasavari H, Abad MEE, Yekaninejad MS. The Effects of Foot Reflexology on Anxiety and Physiological Parameters among Candidates for Bronchoscopy: A Randomized Controlled Trial. Eur J Integr Med 2017;177-81. [CrossRef]

12. Günay E, Bağcıoğlu E, Ulaşlı SS, Akar O, Öz G, Coşkun K, ve ark. Impact of Multimedia Information on Anxiety Levels of Patients Candidate for Bronchoscopy. Acta Med Mediterr 2014; 30:49-56.

13. Triller N, Erzen D, Duh S, Primozic M, Kosnik M. Music During Bronchoscopic Examination: the Physiological Effects a Randomized Trial. Interv Pulmonol 2006; 73: 95-9. [CrossRef]

14. El-Hassan H, Mckeown K, Muller AF. Clinical Trial: Music Reduces Anxiety Levels in Patients Attending for Endoscopy. Aliment Pharmacol \& Ther 2008; 30: 718-24. [CrossRef]

15. Öner N, Le Compte A. Süreksiz Durumluk/Sürekli Kaygı Envanteri El Kitabı. İstanbul: Boğaziçi Üniversitesi Yayınları; 1983; 1-26.

16. Rand D, Blaikley J, Booton R, Chadhuri N, Gupta V, Khalid S, et al. British Thoracic Society Guideline for Diagnostic Flexible Bronchoscopy in Adults. Thorax 2013; 68: i1-i44. [CrossRef]

17. Türk Toraks Derneği (2016). Akciğer kanseri yol haritası Erişim adresi: http://www.toraks.org.tr/userfiles/file/YOLHARITASI.pdf Erişim tarihi: 15.06 .2018

18. Choi SM, Lee J, Park YS, Lee CH, Lee SM, Yim JJ. Effect of Verbal Empathy and Touch on Anxiety Relief in Patients Undergoing Flexible Bronchoscopy: Can Empathy Reduce Patients' Anxiety?. Interven Pulmonol 2016; 92: 380-88. [CrossRef]

19. Navidian A, Tabas E, Muolai N, Soleymani SH. The Effect of Audiovisual Distraction on Anxiety and Satisfaction in Patient Undergoing Bronchoscopy of Imam Ali (As) Hospital In Zahedan. Iran J Psychiatr Nurs (IJPN) 2016; 4:1-10. 